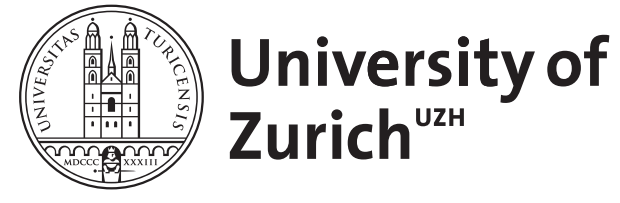

Zurich Open Repository and Archive

University of Zurich

University Library

Strickhofstrasse 39

CH-8057 Zurich

www.zora.uzh.ch

Year: 2007

\title{
A temperament approach to humor
}

Ruch, Willibald ; Köhler, G

Posted at the Zurich Open Repository and Archive, University of Zurich

ZORA URL: https://doi.org/10.5167/uzh-77944

Book Section

Published Version

Originally published at:

Ruch, Willibald; Köhler, G (2007). A temperament approach to humor. In: Ruch, Willibald. The sense of humor : explorations of a personality characteristic / Broschur - Veröffentlicht: 30. Juli 2007. Berlin: De Gruyter, 203-230. 


\title{
A temperament approach to humor
}

\author{
WILLIBALD RUCH and GABRIELE KÖHLER
}

There is both interindividual (i.e., between individuals) and intraindividual (i.e., across situations) variation in humor behavior. Some people tend habitually to appreciate, initiate, or laugh at humor more often, or more intensively, than others do. In everyday language this enduring disposition typically is ascribed to the possession of a "sense of humor" and various type nouns (e.g., cynic, wit, wag) and trait-describing adjectives (e.g., humorous, witty, cynical) exist to describe individuals extreme in one form or the other. Aside of interindividual differences with a relative stability over time there are also actual dispositions for humor which do vary over time. We are all inclined to appreciate, initiate, or laugh at humor more at given times and less at others. In everyday language phrases like to be in good humor, in the mood for laughing, out of humor, ill-humored, in a serious mood or frame of mind etc. refer to such states of enhanced or lowered readiness to respond to humor or act humorously.

\section{The temperamental basis of humor}

In the present chapter we present a state-trait approach relevant for the behavioral and experiential domain of humor. We argue that cheerfulness, seriousness, and bad mood as traits form the temperamental basis of humor, and that cheerfulness, seriousness, and bad mood as states represent intrapersonally varying dispositions for humor. The present approach considers that humor is not (a) unidimensional (people differ on more than one dimension), (b) unipolar (humorlessness needs to be represented as well), and (c) covers affective and mental factors (the dispositions need to relate to moods/temperaments and frame of mind). Furthermore, (d) it acknowledges that the disposition for humor varies intra- and interpersonally and that the utilization of the same concepts as both states and traits allows us to study the relevance of homologous actual and habitual dispositions. Finally, (e) while we attempt to define some traits considered to be relevant for the domain of behavior a "sense of humor" concept should predict, we do not (yet) utilize this concept. We take the position that the "sense of humor" is still more of a folk-concept and has 
not been explicitly converted into a scientific construct so far; furthermore, the model to be presented originated from the experimental study of the emotional responses to humorous stimuli (e.g., Ruch 1995c) and does not claim to be comprehensive for all sorts of humor-related behaviors. Finally, in the sense that humor is a socio-cultural construct, seen as an attitude or world view that allows one to perceive and react to the world in ways that are forebearing and lenient (vs. the cold sharpness of satire), clearly, our approach is more restricted and does not provide a measure for this view of the "sense of humor". But, most important, we assume that while the expression of humor may be culture specific and differ over time, the affective and mental foundations of humor will more likely be universal. Thus, while we agree that pursuing a comprehensive description of habitual individual differences in humor is important, we also think it is a viable alternative to specify and measure the presumable dimensions underlying humor behavior and experience, implement these constructs into humor theories and examine the predictive and even explanatory relevance of the identified traits and states in empirical studies.

A temperamental approach is not incompatible with understanding humor as a world view (one that helps maintain good humor despite adversity). Though this has been related to philanthropy, maturity, optimistic reflection, insight, wisdom, contemplation, seriousness, or even spirituality, it can also be linked to an affective foundation. Even in this tradition it has often been emphasized that a humorous world view is based on a cheerful temperament (perhaps developed due to prior suffering, pain, and exposure to other adverse life experiences). Viewing cheerfulness as an innate affect-based temperament forms a necessary but not sufficient condition for the development of a humorous attitude (which itself is a mental and not an affective quality) and has helped to mold the notion of a temperamental basis of humor. However, we also saw the need to include bad mood and seriousness.

The scope of the present approach is not restricted to "humor" in the above described narrow sense, but transcends it to match the boundaries of the current understanding of humor as an umbrella-term for all the behavioral and experiential phenomena of the field. While we also consider phenomena of humor in the narrow sense, such as "keeping vs. losing one's humor during adversity" or "taking something in good humor", wherever possible, we have attempted to adopt a modern view on this.

\section{A state-trait model of cheerfulness, seriousness, and bad mood}

The need for a state-trait model of cheerfulness, seriousness, and bad mood arose from the experimental study of the emotional responses to humor (Ruch 1990). The 
term exhilaration was proposed, according to its Latin root (hilaris $=$ cheerful) to denote this emotion: the process of becoming cheerful or the temporary raising and fading out of a cheerful state (Ruch 1993a) ${ }^{\dagger}$. This included the description of behavioral, physiological, and experiential components as well as covering exhilarants (i.e., the stimuli and situations capable of inducing exhilaration by such diverse means as humor, tickling, and laughing gas) and the situational, actual and habitual organismic factors facilitating or inhibiting the release of exhilaration were discussed.

Within this framework, it was postulated that cheerfulness, seriousness, and bad mood affect the individual's actual or habitual degree of exhilaratability; i.e., readiness to respond to a humor stimulus with positive affect and laughter. More precisely, it was suggested that the concepts represent actual (state) and habitual (trait) dispositions for lowered (cheerful) and enhanced (seriousness, bad mood) thresholds for the induction of exhilaration or other forms of humor behavior. Thus, cheerfulness as a mood state (or a more tonic change in mood) would be separated conceptually from the emotion of exhilaration (as a temporary, more intense rise in cheerful state observable in behavior, physiology, and emotional experience). A cheerful mood is characterized by its longer duration, fewer fluctuations in intensity, and greater independence from an eliciting stimulus. Single incidents of exhilaration are of short duration and have a marked timing; typically, there is a more or less steep onset, a pronounced apex, and a generally less steep offset, lasting, at most, a few seconds (Ruch 1993a).

While the study of exhilaration or amusement was the major starting point for the development of this model; the assumption is that the utility of the concepts is much broader and might even transcend the field of humor research.

\section{Facet definition of states and traits}

Cheerfulness, seriousness, and bad mood were operationalized by generating five, six, and five facets or definitional components (see Table 1 for short versions of these definitions, and Ruch et al. 1996 for more details). For each concept there is at least one facet describing that the respective state occurs more often, lasts longer, and is of higher intensity than the average ( $\mathrm{CH} 1, \mathrm{SE} 1, \mathrm{BM} 1, \mathrm{BM} 2$, and BM4). At least one further facet of each concept describes the behavior of prototypical persons

Current dictionaries list two meanings for "exhilarate". One is "to make cheerful or merry" and the other "to enliven; invigorate; stimulate" (Webster's encyclopedic unabridged dictionary of the English language; 1989). Thus, the proposed usage of the term neglects the latter part. 
in a specifically cheerful environment or their response to exhilarating situations and stimuli and the generalized attitude towards that field (CH5, SE6, BM3, and BM5). As a state, the concepts were represented by (1) the presence of the mood qualities (as included in the core facets of the trait definitions), and (2) the presence of the respective action tendencies (see Table 2).

The empirical evaluation of the state and trait facet models utilized samples of German and American adults comprising more than 1,300 adults each. The hypothesized trait facet structure emerged, as predicted, and appeared to be highly generalizable across different samples (Ruch et al. 1996). The elaboration of the state facet model included the study of both inter- and intraindividual variation and the resulting item factor structure (and the location of the components in the three-dimensional space) was highly comparable (Ruch et al. 1997).

Table 1. Short descriptions of the definitional components of the trait concepts

\begin{tabular}{|c|c|}
\hline Facets of & Short description \\
\hline \multicolumn{2}{|c|}{ Trait cheerfulness } \\
\hline $\mathrm{CHI}$ & Prevalence of cheerful mood \\
\hline $\mathrm{CH} 2$ & Low threshold for smiling and laughter \\
\hline $\mathrm{CH} 3$ & Composed view of adverse life circumstances \\
\hline $\mathrm{CH} 4$ & Broad range of active elicitors of cheerfulness and smiling/laughter \\
\hline $\mathrm{CH} 5$ & Generally cheerful interaction style \\
\hline \multicolumn{2}{|c|}{ Trait seriousness } \\
\hline SE1 & Prevalence of serious states \\
\hline SE2 & $\begin{array}{l}\text { Perception of even everyday happenings as important and the tendency to } \\
\text { consider them thoroughly and intensively (rather than superficially) }\end{array}$ \\
\hline SE3 & $\begin{array}{l}\text { Tendency to plan ahead and set long-range goals (and attaining the closest } \\
\text { possible harmony with these goals in every action and decision) }\end{array}$ \\
\hline SE4 & $\begin{array}{l}\text { Tendency to prefer activities for which concrete, rational reasons can be } \\
\text { produced (thereby considering activities which don't have a specific goal as a } \\
\text { waste of time and nonsense) }\end{array}$ \\
\hline SE5 & $\begin{array}{l}\text { Preference for a sober, object-oriented communication style (saying exactly } \\
\text { what one means without exaggeration or ironic/sarcastic undertones) }\end{array}$ \\
\hline SE6 & $\begin{array}{l}\text { Humorless attitude about cheerfulness-related behavior, roles, persons, } \\
\text { stimuli, situations, and actions }\end{array}$ \\
\hline \multicolumn{2}{|r|}{ Trait bad mood } \\
\hline BM1 & Prevalence of bad mood \\
\hline BM2 & Prevalence of sadness (i.e., despondent and distressed mood) \\
\hline BM3 & $\begin{array}{l}\text { Sad behavior in cheerfulness evoking situations, the attitudes toward such } \\
\text { situations and the objects, persons, and roles involved }\end{array}$ \\
\hline BM4 & Prevalence of ill-humoredness (i.e., sullen and grumpy or grouchy feelings) \\
\hline BM5 & $\begin{array}{l}\text { Ill-humored behavior in cheerfulness evoking situations, the attitudes toward } \\
\text { such situations and the objects, persons, and roles involved }\end{array}$ \\
\hline
\end{tabular}


Table 2. The definitional components of the state concepts

\begin{tabular}{|c|c|}
\hline Facets of & Short description \\
\hline $\begin{array}{l}\text { State cheerfulness } \\
\text { cheerful mood } \\
\text { hilarity }\end{array}$ & $\begin{array}{l}\text { Presence of a cheerful mood state (more tranquil, composed) } \\
\text { Presence of a merry mood state (more shallow, outward) }\end{array}$ \\
\hline $\begin{array}{l}\text { State seriousness } \\
\text { earnestness } \\
\text { pensiveness } \\
\text { soberness }\end{array}$ & $\begin{array}{l}\text { Presence of an earnest mental attitude, task-oriented style } \\
\text { Presence of a pensive or thoughtful mood state } \\
\text { Presence of a sober or dispassionate frame of mind }\end{array}$ \\
\hline $\begin{array}{l}\text { State bad mood } \\
\text { sadness/melancholy } \\
\text { ill-humor }\end{array}$ & $\begin{array}{l}\text { Presence of a sad or melancholy mood state } \\
\text { Presence of an ill-humored (grumpy or grouchy) mood state }\end{array}$ \\
\hline
\end{tabular}

The relationships between the three concepts were outlined and tested and it was found that cheerfulness is negatively correlated with both seriousness and bad mood (with the coefficients being smaller for the former and higher for the latter). Seriousness and bad mood are slightly positively correlated. The same pattern of relationship emerged for states and traits. However, for the former, the coefficients are supposed to depend on the type of situation and also to be higher.

\section{The State-Trait-Cheerfulness Inventory - STCI}

Two versions of the trait part were constructed, the component form with 106 items (STCI-T $<106>$ ) and the standard form with 60 items (STCI-T<60>). Cronbach alpha coefficients ( .86 to .96 for the STCI-T $<106>; .80$ to .94 for the STCI-T $<60>$; Ruch et al. 1996) and retest reliability (.77 to .86 for STCI-T $<106>$, interval of 4 weeks, $N=103 ; .73$ to .86 for STCI-T $<60>$, interval of 3 weeks, $N=68$ ) turned out to be high. A peer-evaluation form was generated by reformulating all items in a he/she-version and by adapting the instructions accordingly. The correlations between self- and peer-evaluation turned out to be sufficiently high (Ruch et al. 1996).

The construction of the standard state form ( 30 items; STCI-S $<30>$ ) was based on several criteria including the sensitivity of items for mood alterations. The scales' internal consistency were satisfactory (alpha coefficients from .85 to .94 ; Ruch et al. 1997) and the test-retest correlation in the first above mentioned sample was low (.33 to .36). Modified versions of the STCI-S (with instructions to describe the predominant mood states of last week, last month, and last year) were created for the assessment of longer-lasting mood states. Standard and short versions of both parts were subsequently developed for English speaking populations. 


\section{The role of the humorous temperaments in humor}

Both theoretical and empirical accounts point towards these concepts' relevance for research on humor. Due to their different nature and hedonic tone, cheerfulness and bad mood (as socio-affective dispositions) and seriousness (as a habitual frame of $\mathrm{mind} / \mathrm{view}$ of, and attitude toward the world) will be predictive of different aspects of humor. While one can expect that some aspects of humor will be related to only one of the concepts, others will involve all three.

Cheerfulness might be relevant for affective responses to exhilarating stimuli and situations but also for the engagement or creation of such situations. First evidence for the relevance of state cheerfulness comes from an early study that found a positive correlation of .28 between retrospectively reported cheerful mood during the last 24 hours and laughter during that time span (Young 1937). More recently, an index of state cheerfulness predicted facial exhilaration in response to humor in two studies (Ruch 1990, 1995c), confirming that state cheerfulness predisposes one to hyperexpressiveness; i.e., more cheerful individuals smile and laugh at lower levels of perceived funniness than less cheerful persons do. It turned out across the two studies that the narrow concept of cheerfulness (composed of some elation items of a multidimensional mood scale) yielded higher coefficients than the more global concepts of positive mood located at three levels of the hierarchy (i.e., elation, general well-being, positive affectivity) in the model. Using the STCI-S, Ruch (1997) found that state cheerfulness predicted smiling and laughter in response to a clowning experimenter and a humorous videotape.

Trait cheerfulness is related to humor in a variety of ways; the type of relationship postulated depends to some extent on what is understood by "humor." Trait cheerfulness represents the temperamental disposition for good humor; i.e., individuals high in trait cheerfulness will be in cheerfulness states more often, and be serious or in a bad mood less often than their low-cheerful counterparts. This might relate to a lowered threshold for coming into cheerful states and enhanced thresholds for the antagonistic ones. Moreover, trait cheerfulness might account for the phenomenon of keeping or losing humor when facing adversity. Thus, we hypothesize that trait cheerful individuals can't be brought out of cheerful states as readily as low trait cheerful people. Furthermore, trait cheerfulness is a predictor of the intensity of affect; once induced, states of cheerful mood or hilarity are more pronounced among the trait cheerful individuals and more often attain the level of smiling and overt laughter. Thus, trait cheerfulness is also seen as a disposition for the emotion of exhilaration which covers the higher extent to which cheerful affect is induceable. Finally, cheerfulness will not only be related to affective responses to humor but also to the initiation (entertainment not creation) of humor behaviors in social situations. 
Trait cheerfulness is a unipolar construct and the low pole of this dimension can only partially account for the phenomenon referred to as "humorlessness". We argue that it is necessary to distinguish at least among two forms of this: one describing a mental quality of taking events and situations as being too important and serious, the other referring to an affective quality of being predominantly in bad humor, often ill-humored, or coming "out of humor" easily. While seriousness and bad mood have been chosen to cover these two forms of humorlessness, we nevertheless expect both to be positively related to some forms of humor.

Dictionaries often list seriousness as a synonym of humorlessness. Not surprisingly, then, seriousness as a trait was seen as a marker of the low pole of the sense of humor (e.g., Svebak 1996) and a "serious mood or frame of mind" was seen as antagonistic to humor while a "playful set or frame of mind" is favorable (e.g., McGhee 1979a). One can expect that seriousness as an actual or habitual mental attitude will be involved in both the encoding and decoding of humorous messages. There is a heterogeneous set of dimensions that provide links to humor; for example, one can mean something seriously or in fun; have earnest intentions or only be kidding; take things importantly or lightly; be immersed in something significant vs. frivolous; prefer to involve oneself in profundities or superficialities, etc.

Indeed, various aspects of trait seriousness (or the lack thereof) have been the subject of formal theories of humor. McGhee (1996) listed seriousness and playfulness as crucial factors underlying a sense of humor. For McGhee (1979a), humor is a form of play - playing with ideas. While people might be very good at spotting the incongruities, absurdities, and ironies of life, only mentally playful persons will find humor in them. Through socialization people lose the ability to be playful and be light; the (re)activation of a playful attitude or outlook triggers the other components of the sense of humor. Raskin (1985) distinguishes between the bona-fide (serious, truth-committed) mode of communication and the non-bona-fide (humorous) mode of joke telling and argues that switching easily and readily from one mode to another is one (of three) defining element of a sense of humor. This volitional aspect of the sense of humor Raskin sees as related to a dimension of serious vs. humorous: The extremely serious individual wants to function exclusively in the bona fide mode of communication and seriousness involves a lack of humor generation and appreciation. (The latter will be elaborated in a later section.)

As already acknowledged by Hermann Ebbinghaus (1913), however, humor research also needs a concept of state seriousness to account for the fact that individuals' tendency, preparedness, and readiness to engage in humorous interactions differ over time. Indeed, in the reversal theory seriousmindedness plays an important role by defining the telic or goal-oriented metamotivational state, while playfulness marks its obverse, the paratelic or non goal-oriented state (Apter \& Smith 1977). Here, the success of a humor stimulus is seen to be contingent on the presence of 
the latter. Svebak and Apter (1987) report that a funny videotape changed participants' state to paratelic (as indicated on a 6-point scale of serious-playful). While the rating of state seriousness correlated negatively with the frequency of laughter, this correlation just failed to reach the level of significance (for the reversal theory account of humor, see, for example, Apter 1982).

Finally, it should be noted that models of the elicitation of humor and laughter incorporate seriousness or related concepts. Laughter is considered to be preceded by a sudden annulment of seriousness (Frijda 1986), consists of the buildup of strain or tension and its abrupt relief (Sroufe \& Waters 1976; Wilson 1979), or includes the evaluation that the setting in which the incongruity is processed is "safe" (i.e., nondangerous, non-serious; Rothbart 1976). Although not overtly stated in these theories, one might postulate that these processes are moderated by individual differences in seriousness. Furthermore, serious issues might be excluded from topics one is willing to laugh or joke about. Thus, both state and trait seriousness are linked to various aspects of humor and ought to be included more systematically in empirical studies of humor and laughter.

Blends of cheerfulness and seriousness. The fact that cheerfulness (as an affective state or temperament) and seriousness (as a quality of the frame of mind/mental attitude or world view) are of different nature and only slightly negatively correlated suggests that we could consider them in tandem. It appears that the form of humor of cheerful individuals will be very different depending on the degree of seriousness. For example, Lersch argued that while humor (in the narrow sense) is based on cheerfulness, it is serious as well in that it contains the wisdom that nothing earthly and human is perfect. In this respect, humor is different from merriment/ hilarity. The former is contemplative, pensive, and profound, the latter thoughtless, superficial, and shallow (Lersch 1962). This view allows the hypothesis that humor (in its narrow sense) is a blend of cheerfulness (as a temperament or prevalent mood) and seriousness (as a mental quality); while more shallow forms of humor are blends of cheerfulness and low seriousness. In other words, it will be the high cheerful/low serious person who laughs at slapstick, shallow comedies, practical jokes, etc. and the high cheerful/serious person who "smiles benevolently" at the imperfections of world and humans.

Bad mood as a form of humorlessness has not yet received the attention it deserves in humor research. This is surprising, since expressions like out of humor, ill-humored etc. clearly indicate the links between humor and negative affectivity. States of cheerfulness and bad mood appear to be opposites in that one hardly can be cheerful and in a bad mood simultaneously; therefore, the successful induction of a cheerful state implies replacing the bad mood or reducing its intensity and prevalent bad mood would hinder the induction of cheerfulness and laughter. Indeed, while baseline negative mood levels did not predict humor appreciation (Ruch 1990; 
Wicker et al. 1981), induced states of negative affect did (e.g., Prerost 1983b). However, someone in a bad mood might be prone to negative humor; e.g., enjoy humor of misanthropic quality or produce sarcastic remarks.

The role of trait bad mood has recently been acknowledged by McGhee (1996) who listed negative mood as one of eight defining components of low sense of humor. While other conceptualizations of the sense of humor do not explicitly include this affective form of humorlessness, items of scales sometimes relate to bad mood; nevertheless, finer distinctions need to be drawn among several forms of "humorlessness." While both serious individuals and those in a bad mood may be perceived as humorless, the reasons are different. In the latter case, the generation of positive affect is impaired by the presence of a predominant negative affective state; in the former, there is lowered interest in engaging in humorous interaction or in switching to a more playful frame of mind; i.e., a stronger aspect of volition is involved. There may be differences among bad mood facets as well. While an ill-humored person, like the serious one, may not want to be involved in humor, the person in a sad mood may not be able to do so even if he or she would like to. Also, while the sad person is not antagonistic to a cheerful group, the ill-humored one may be.

Bad mood might also be a disposition facilitating certain forms of humor. Remplein (1956) argued that the lack of kindness among grumpy and grouchy types makes them react to inadequacies of fellow people with mock, irony, cynicism, and sarcasm rather than with empathetic smiling (as the humorous persons would). Thus, bad mood as a trait might relate to humor positively and negatively.

\section{Validity of the temperament approach to humor}

The postulate that cheerfulness, seriousness, and bad mood form the temperamental basis for humor needs empirical verification. One means would be to use these traits as moderator variables in humor experiments and test whether they predict interindividual differences in humor behavior. Another would be to demonstrate that the three traits correlate highly with traditional sense of humor scales or load on the same factors in joint factor analyses.

The results regarding the role of trait cheerfulness in humor are presented first. Figure 1 illustrates the context that guided studies and the research questions posed.

Trait cheerfulness as a disposition for state cheerfulness

The state-trait model of cheerfulness assumes that while everybody is in a cheerful state now and then, individuals high and low in trait cheerfulness will differ with re- 


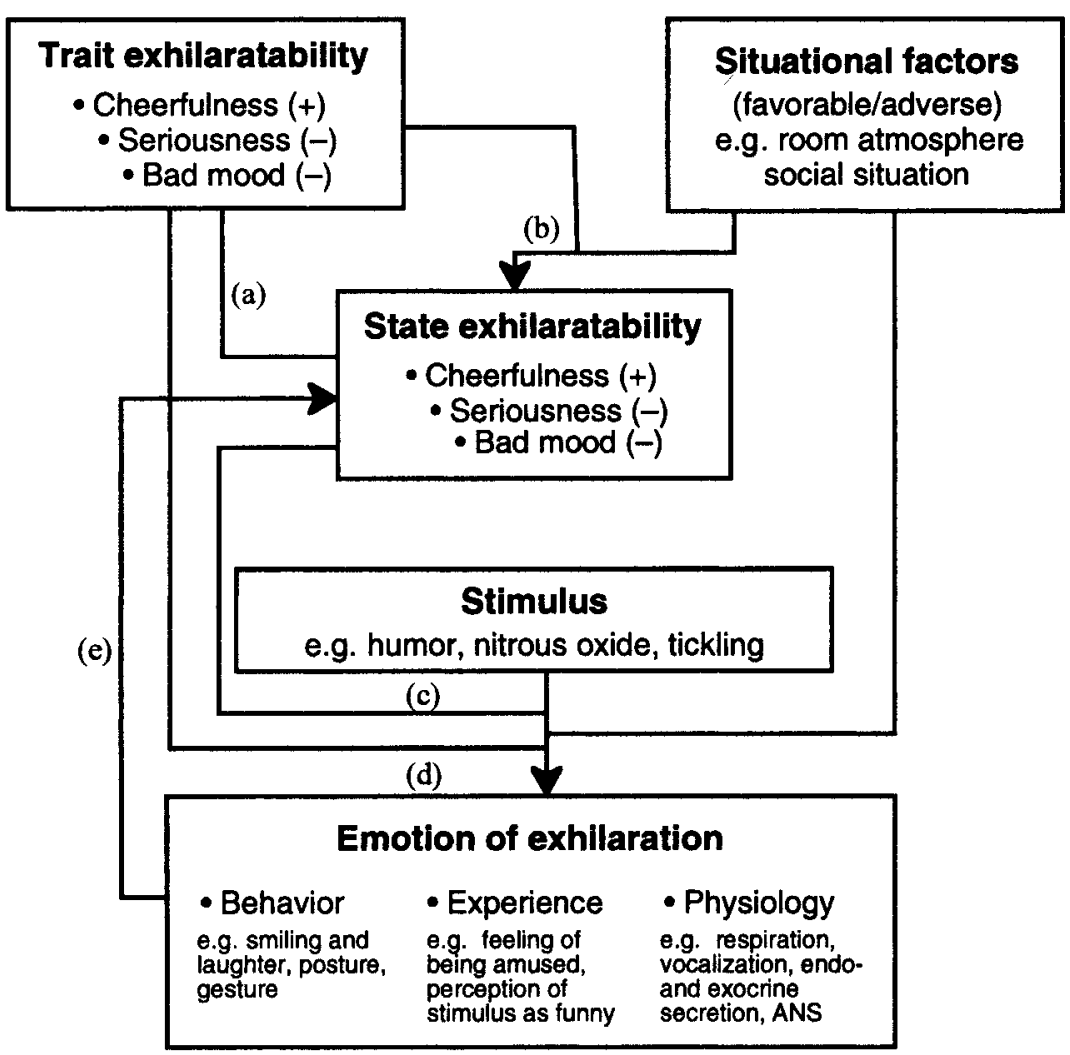

Figure 1. Diagram of variables and their relationship. Research questions related to (a) the study of the state-trait relationship, (b) how trait cheerfulness moderates the effect of adversity on mood, whether (c) state and (d) trait cheerfulness represent dispositions for smiling and laughter, and (e) the effect of smiling/laughter on mood

spect to the threshold, frequency, intensity, and duration of state cheerfulness. Furthermore, it is postulated that cheerful states are more robust among those high in trait cheerfulness (as compared to the lows). This parameter of robustness was introduced to relate to the phenomenon of "keeping or losing one's humor"; maintaining a good mood when facing adversity or getting out of humor easily. The assumption is that the prevalence of cheerful mood among trait cheerful individuals not only refers to their tendency to come into that state easily but also to maintain it. Especially those low in the facet of cheerful composure should be the ones getting ill-humored easily. 
First support for this hypothesis comes from the joint factor analysis of state and trait items (Ruch et al. 1997) confirming that while homologous states and traits form distinguishable factors they are positively intercorrelated. The convergence between states and traits was also confirmed utilizing peer-evaluations for the assessment of traits, ruling out the alternative interpretation that positive correlations of homologous concepts emerge only due to identical observer perspective.

A subsequent rating study (Ruch \& Köhler in press) examined the further parameters of the state-trait relationship in a sample of 92 students of both sexes. For each of the 30 items of the state part of the STCI, the participants indicated how easily they come into the state (threshold in), how intense they experience the state described by the item (intensity), how long that state typically lasts (duration), and how much it takes to bring them out of that state (robustness, or threshold out). The ratings were summed across the items of a scale and the total scores were correlated with the trait scores. It turned out that there generally was a convergence of homologous scales (all $p s<.001$ ), in other words that the three trait scales correlated positively with the intensity, duration, threshold, and robustness of the state scales labeled equally. There were also interesting patterns between non-homologous scales: for example, trait cheerfulness correlated negatively with all parameters of state seriousness and state bad mood, i.e., it takes much to bring high trait cheerful individuals (compared to the low scorers) into these two states, little to make these states vanish, and the typical intensity and duration of these states is low.

Taken together the results of this rating study suggest that the trait cheerful peoples' prevalence of state cheerfulness is facilitated by a disposition to acquire easily and maintain this mood, fostered by enhanced thresholds for the induction of antagonistic states. While the study largely confirmed the predictions, it is obvious that the phenomenon of robustness of mood, i.e., the tendency of trait cheerful individuals to maintain in cheerful mood even under adverse circumstances, should be further studied in an experimental setting.

\section{Trait cheerfulness and keeping humor under adversity}

The present model provides all the constructs necessary to describe the formula that some people (presumably those with a sense of humor) "keep humor" when facing adversity while others (those lacking it) do not. The former may refer to the tendency of individuals to maintain a high level of state cheerfulness and retain a low level of state bad mood in the presence of factors suiting to induce negative mood; i.e., there will be no (or only little) change in STCI-S CH and STCI-S BM prior to the onset of adversity and after. The reverse, i.e., "losing humor" might refer to the tendency of individuals to drop in state cheerfulness and get into a bad mood state as 
a result of the negative event; i.e., the STCI-S CH scores decline (negative pre-post differences) and the ones of STCI-S BM increase (positive pre-post differences). "Adversity" requires stimuli or situations with the potential to shift an individual's mood into negative directions and/or induce negative affects. At best, such a mood induction procedure is veiled or unobtrusive and of moderate intensity (to allow for interindividual variance in responses). The "sense of humor" is replaced by the cheerful composure facet of trait cheerfulness, and the individuals "having" or "lacking" humor are determined by median split, or form the extreme groups on the respective dimension.

Thus, for example, in an experimental situation where annoyance is induced, the prediction is that trait cheerful individuals will be less prone to show facial, physiological, or experiential signs of anger and they will not shift into a bad mood while those low in trait cheerfulness (or cheerful composure) will show negative affect more often and will increase in the ill-humor component of STCI-S BM. While this hypothesis has not yet been put to extensive empirical testing, there is already some support from both published and unpublished experiments, which will be briefly reviewed. First, however, a reanalysis of a recent study provides new and supplemental evidence.

A thought experiment. When constructing the STCI-S, it was necessary to demonstrate that the state items are sensitive to change. One of the studies $(N=35)$ involved a thought experiment (see Ruch et al. 1997) in which participants were not exposed to, or tested in, state-relevant situations, but rather were provided with different scenarios (describing state-relevant prototypical situations). They were instructed to imagine these situations and then to evaluate (using the STCI-S) how an average person exposed to such situations would feel. To match the facets of the state scale, there were two (cheerfulness, hilarity), three (earnestness, pensiveness, soberness), and two (melancholy, ill-humor) scenarios for the cheerfulness, seriousness, and bad mood constructs, respectively. For control purposes, a neutral scenario was depicted as well. None of the mood-describing terms of the STCI-S items were used in the scenarios. Figure 2 gives the two bad mood scenarios .

To clarify whether cheerful composure moderates the perceived potential of the idealized melancholy and ill-humor situation to induce bad mood, a 2x3-ANOVA with cheerful composure ( $\mathrm{CH} 3$ ) as grouping variable (median split) and the neutral, melancholy, and ill-humored scenario as repeated measurement factor was computed for the three STCI-S scales. The expected interaction emerged for state bad mood $(\mathrm{F}[2,62]=3.968 ; p=.024)$. Planned means comparisons showed that while people habitually high and low in cheerful composure did not differ in the neutral scenario, the highs expected a lower degree of state bad mood under the melancholy and illhumor condition than did the lows (see Figure 3 ). While obviously composed indi- 
The melancholy scenario. The cold, gray November morning lay leaden over the city. Tired and exhausted I lay on the thoroughly tousled bed. The unexpected death of a friend weighed on my thoughts; I felt empty, incapable of undertaking any small thing, incapable even of thinking clearly - I was lame with sorrow. A cold wind blew the rain against the window and the heavily overcast skies made the world outside seem even darker and more melancholy. No daylight came in through the window and the sole lamp only faintly illuminated the room. Again and again I asked myself in anguish, why must our lives be burdened with sickness, suffering and death, and for that matter, if there is a reason to continue living at all. The darkness of the room seemed to engulf my whole soul, and I wasn't at all able to divert myself from these broodings even by thinking about common everyday things.

The ill-humor scenario. To start things off, I got up on the wrong side of the bed. The water suddenly turned ice cold while I was showering, because the electricity was shut off. The mail consisted only of bills and a note of payment which I had already taken care of. The neighbor's cat had torn up the newspaper, and the faucet in the bathroom began to drip again as it had been doing all night. One month ago, I lost my job, and I really find the rejections of the last couple of days unjust. The telephone rings perhaps it's about the job offer which was in the newspaper yesterday, and for which one was supposed to call back today. It takes me 5 minutes to convince a hard of hearing woman who wants to talk to her daughter-in-law, that she has the wrong number. When I go out to the car in order to go shopping, I find a flat tire. And as I'm changing that, it starts to rain. When a passing motorist asks me how to get to the railroad station, I grumble something rather rudely at him, without giving a definite answer.

Figure 2. The two scenarios representing the facets of bad mood

viduals admit that these adverse situations are capable of bringing everybody "out of humor," they expect a significantly weaker impact. No such effect emerged for state cheerfulness or seriousness $(\mathrm{F}[2,62]=.73$ and 1.75 , respectively, all ns). More important, separating participants according to trait bad mood did not yield effects either, no matter whether the scale $(\mathrm{F}[2,62]=.57)$ or the facets of melancholy $(\mathrm{F}[2,62]=1.11)$ or ill-humor $(\mathrm{F}[2,62]=.77$, all $\mathrm{ns})$ were used as classification variables. This rules out the alternative interpretation that the effects found for cheerful composure are just the hidden obverse effects of trait bad mood.

Experimental evidence. The hypothesis that trait cheerfulness (and in particular the facet of cheerful composure) represents a disposition for robustness of prevailing cheerful state receives support from three experiments. Ruch and Köhler (in press) attempted to induce mood changes unobtrusively by exposing 72 non-psychology students to one of three experiment rooms prepared to provide prototypical cheerful, serious, or bad mood atmospheres. These qualities were achieved by varying degrees of light, color, size/space, and interior/equipment. For example, a room with an ex- 
pansion of about $20 \mathrm{~m}^{2}$, large windows, and yellow walls was used as the basis for creating a cheerful atmosphere. There were also funny posters, balloons, garlands, and colored draperies and participants were told that the usual room is unavailable, so the experiment needs to take place in this room which has been prepared for a birthday party. By comparison, the depressing room was about $90 \mathrm{~m}^{2}$ and was painted black. The room was only lighted by a small frosted bulb. The participants performed a variety of tasks (e.g., filling in questionnaires; drawing a picture) in all three rooms. Their mood states were assessed after both a short and a long period in their assigned room. Individuals low in cheerful composure (i.e., facet $\mathrm{CH} 3$ ) displayed a decrease of state cheerfulness and an increase of bad mood when being exposed to the adverse circumstances (the "serious" and "bad mood" rooms), while highly composed persons maintained their degree of state cheerfulness and did not get in a bad mood in these rooms.

Wancke (1996) had 68 adults explain the meaning of five affect-laden proverbs (cheerful vs. ill-humored/melancholic) in either a rational/sober or playful way. When explaining proverbs of negative content, individuals low in trait cheerfulness talked themselves into a bad mood while the trait cheerful people maintained their mood state. There was no such effect for the groups interpreting the proverbs of a cheerful tone. Finally, Hartig (1996) studied the moderating role of cheerful composure in the mood-changing effects of visual feedback of voluntary facial expression in 49 students. They were instructed to perform single facial actions which eventually added up to a pose of either an emotional negative or a neutral quality. While they kept this pose for a time span of 10 seconds, unexpectedly a mirror was uncovered in front of them, giving the students visual feedback (in addition to the mere interoceptive feedback of muscle contraction) of their facial expression. Pretesting as well as affect ratings confirmed this procedure to be perceived as affective-ly negative by some; however, individuals high in cheerful composure (compared to the lows) displayed a higher rate of smiling and laughter than those below the median in cheerful composure.

While this hypothesis needs further experimental confirmation, the existing data support the view that trait cheerfulness (and particularly the facet of cheerful composure) moderates the effects of the induction of negative affects and moods. Future experiments need to study the appraisals of the adverse situations. So far it is unclear why trait cheerful individuals maintain a cheerful mood. Did they appraise the situations as less annoying than the low cheerful participants (and accordingly responded with a lower degree of bad mood), or was the effect based on differences in physiological factors, e.g., a different reactivity of the affective systems involved? A systematic assessment of potentially intervening factors is needed to illuminate why cheerful individuals keep humor in adverse situations and low cheerful people are prone to lose it. 


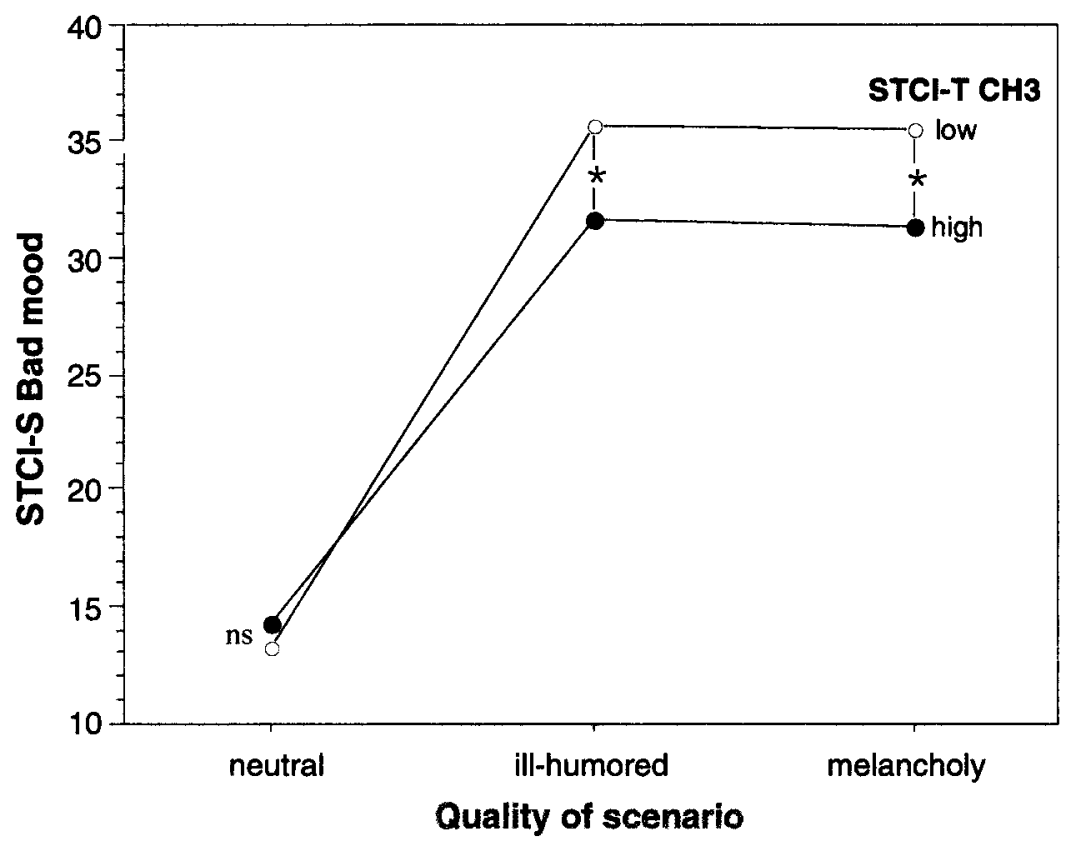

Figure 3. Estimated level of bad mood in mood-relevant scenarios as stipulated by subjects habitually high and low in cheerful composure $* p<.05$.

\section{Trait cheerfulness as a disposition for exhilaration}

It was hypothesized that individuals high and low in trait cheerfulness differ from each other with respect to the facility with which exhilaration (or amusement), smiling/laughter, and - as a consequence - state cheerfulness is induced (Ruch 1995e). Two experiments were carried out to examine the hypothesis that trait cheerfulness moderates the impact of a stimulus on the induction of exhilaration.

A female experimenter involved 60 students in either a jocular or a neutral interaction (lasting 10 minutes) in the midst of an ongoing regular experiment (Ruch 1997). Facial reactions were videotaped through an adjacent one-way mirror and subsequently the frequency, intensity, and duration of facial reactions were analyzed by applying the Facial Action Coding System (Ekman \& Friesen 1978). Mood states were assessed prior to and after the interview with the state part of the STCI. Results showed that individuals high in trait cheerfulness showed a greater improvement of state cheerfulness than low trait cheerful individuals. Furthermore, they showed more and longer-lasting smiling and laughing reactions to the comical 
interview than habitually low cheerful individuals. Finally, they had a shorter latency in remembering a funny event than the low cheerful individuals.

In a further study 20 male volunteers took part in two experimental sessions one week apart in which they inhaled either a mixture of nitrous oxide and oxygen (4 trials) or pure oxygen ( 1 trial). Mood states and facial responses were recorded. Cheerful mood increased under nitrous oxide for trait-cheerful individuals as compared to placebo and baseline measures, which did not differ from each other indicating that placebo control was successful. No such effect could be observed for low trait-cheerful participants. Furthermore, trait cheerful individuals showed smiling and laughter more often than low trait cheerful individuals did (Ruch \& Stevens 1995). The effects were stable across the one-week interval.

These results support the notion of a temperamental basis to humor. The laughter induced by laughing gas is not triggered by cognitive factors as is the one induced by humor; "taste" or humor preferences do not play a role. The results seem to demonstrate that there is a disposition for laughter in the sense that thresholds differ for people: whatever the stimulus, and given all other processes and appraisals being equal, individuals high in trait cheerfulness will be more likely to laugh than those low in trait cheerfulness. Perhaps even under more demanding situations, the trait cheerful people might be the ones that are more likely to smile and laugh. Since episodes of laughter are mood-enhancing, this allows us to speculate another pathway to explain how individuals high in trait cheerfulness will experience states of cheerfulness more often than those low in trait cheerfulness.

\section{Seriousness and appreciation and creation of humor}

Prior studies on the relationship between creation and appreciation of humor have shown that they are uncorrelated (e.g., Koppel \& Sechrest 1970). Consequently, two things need to be considered when testing the hypothesis that trait seriousness relates to both humor appreciation and humor creation. First, given their independence, one can not expect that both creation and appreciation of humor correlate highly with trait seriousness. Second, as a consequence, additional variables are needed for a prediction of humor creation and appreciation.

Humor creation and appreciation. Koppel and Sechrest (1970) treated both concepts as unidimensional; thus, it might be that positive and negative correlations (potentially to be found for components) were averaged out. For example, high humor creation skills might go along with high enjoyment of sophisticated and low enjoyment of simple forms of humor. To account for this possibility the measures employed in the present study are multidimensional. The measure of humor appreciation is based on a two-mode model that distinguishes among the three stimulus 
categories of incongruity-resolution, nonsense, and sexual humor, and between the two response dimensions of funniness and aversiveness (see Ruch \& Hehl this volume). The humor test (Form K of the 3 WD; Ruch 1983) therefore provided six scores; three for funniness and three for aversiveness of incongruity-resolution (INC-RES), nonsense (NON), and sexual (SEX) humor. Additionally, participants were asked to mark whether they already knew the joke/cartoon or not to see if prior exposure to a greater variety of humor predicts the type or number of humor appreciated or created.

The assessment of humor creation was based on the experimental version of the Cartoon Punch line Production Test (CPPT; Köhler \& Ruch 1993) which provides a separation of quality and quantity of humor production. The CPPT contains 15 caption-removed cartoons of the three humor categories incongruity-resolution, nonsense and sexual humor ( 5 each), and participants are asked to create as many punch lines as they are able to within a period of 30 minutes. The total number of punch lines created (CPPT NP) forms the score for quantity (or fluency) of humor production. Four indicators of quality of wit (or origence) can be derived with the help of a sample of judges, namely wittiness (CPPT WP) and originality (CPPT OP) of the created punch lines and estimated wit (CPPT WI) and richness of fantasy (CPPT FA) of the creator. Both tests were administered to a sample of 110 adults ( 58 women and $52 \mathrm{men}$ ) in the ages of 17 to $83(M=46.00, S D=15.91$ years) who also answered a variety of other instruments (see Köhler \& Ruch 1996). Among them were the STCI and the NEOPI-R (Costa \& McCrae 1992), a measure of the five factor model of personality (FFM), to see if seriousness and general personality dimensions predict wit.

Table 3 shows that, like in earlier studies, humor appreciation and humor creation were largely independent of each. However, those preferring nonsense over incongruity-resolution humor seemed to be better in creating funnier punch lines. This is not surprising since structure preference is correlated with measures of simplicitycomplexity of personality and with indicators of creativity. While knowing humor (at least the items of the $3 \mathrm{WD}$ ) did not facilitate fluency or origence of punch line creation, those who are familiar with more humor items preferred nonsense over incongruity-resolution humor $\left(\mathrm{SPI}_{\mathrm{f}}: r=.34, p<.001 ; \mathrm{SPI}_{\mathrm{a}}: r=-.19 ; p<.05\right.$, $\mathrm{df}=$ 108 ). While the results require a detailed analysis regarding the type of humor produced (e.g., it might be that individuals high in $\mathrm{NON}_{\mathrm{f}}$ tend to produce nonsense humor and individuals high in INC-RES f $_{\mathrm{f}}$ roduce punch lines with completely resolvable incongruities), the orthogonality of the present parameters did not allow to expect high correlations with seriousness.

Trait seriousness and humor creation/wit. The facet definition of trait seriousness includes that serious individuals communicate in a sober and more fact-oriented 
Table 3. Correlations between humor creation and humor appreciation

\begin{tabular}{lccccc}
\hline 3 WDICPPT & NP & WP & OP & WI & FA \\
\hline INC-RES $_{\mathrm{f}}$ & .04 & -.07 & -.06 & -.10 & .00 \\
NON $_{\mathrm{f}}$ & .18 & .15 & .18 & .15 & $.20^{*}$ \\
SEX $_{\mathrm{f}}$ & $.22^{*}$ & .07 & .12 & .11 & $.21^{*}$ \\
INC-RES $_{\mathrm{a}}$ & .02 & -.03 & .07 & .01 & .02 \\
NON $_{\mathrm{a}}$ & -.07 & -.18 & -.09 & $-.19 *$ & -.13 \\
SEX $_{\mathrm{a}}$ & -.13 & -.12 & -.09 & -.15 & -.16 \\
SPI $_{\mathrm{f}}$ & .12 & $.20^{*}$ & $.22^{*}$ & $.23^{*}$ & .18 \\
SPI $_{\mathrm{a}}$ & -.12 & $-.23^{*}$ & $-.21^{*}$ & $-.28^{* *}$ & $-.21^{*}$ \\
Funniness $_{\text {Aversiveness }}$ & .18 & .06 & .10 & .07 & .17 \\
Knowledge & .02 & -.13 & -.06 & -.15 & -.13 \\
\hline
\end{tabular}

Notes. $\mathrm{NP}=$ number, $\mathrm{WP}=$ wittiness, $\mathrm{OP}=$ originality of punch lines, $\mathrm{WI}=$ wit, $\mathrm{FA}=$ fantasy of creator. INC-RES = incongruity-resolution, NON = nonsense, $\mathrm{SEX}=$ sexual humor; $\mathrm{f}=$ funniness, $\mathrm{a}=$ aversiveness; $\mathrm{SPI}=$ structure preference index. $(N=110)$.

${ }^{*} p<.05 ;{ }^{* *} p<.01$.

style; i.e., they prefer to say exactly what they mean without exaggeration or ironic undertones (SE5; see Table 1). The low scorers will more likely mean something in fun, or only be kidding, and can thus be expected to perform better on a test like the CPPT. Depending on their creativity and fantasy the product - the punch line created - will be more or less funny. Recently, we demonstrated that the Eysenckian superfactor of Psychoticism (a marker of creativity) is predictive of quality of humor creation (Köhler \& Ruch 1996). Reanalysing these data we want to examine whether seriousness and Psychoticism overlap in their prediction of wit or supplement each other. Likewise, we want to study Openness to experience, the marker of creativity in the five factor model of personality (FFM).

However, one can be witty without actually creating new humor; telling jokes and funny stories may require factors, such as a humor repertoire, social needs and performance skills, but not necessarily wit. Trait cheerfulness, like several sense of humor scales and even genuine measures of humor creation, emphasizes the entertainment aspect (see Table 1, facet CH5) and hence we do not expect the CPPT to be highly correlated with trait cheerfulness.

Table 4 contains the correlations between indices of quantity and quality of humor production and several putative predictors of wit. While trait cheerfulness correlated positively and trait bad mood correlated negatively with wittiness of punch lines, among the STCI scales it is clearly trait seriousness that best predicted wit both as regards quality and quantity of punch line production. While all facets of seriousness 
Table 4. Correlations between quantity and quality of punch line production and the STCI-T $<60>$ scales and Openness (scale and facets) as measured with the NEOPI-R

\begin{tabular}{lcllll}
\hline & NP & WP & OP & WI & FA \\
\hline STCI-T<60> scales & & & & & \\
$\quad$ Cheerfulness & .10 & $.21^{*}$ & .17 & .15 & .12 \\
Seriousness & $-.26^{* *}$ & $-.45^{* * *}$ & $-.36^{* * * *}$ & $-.42^{* * *}$ & $-.34^{* * *}$ \\
Bad mood & -.08 & $-.22^{*}$ & -.18 & -.14 & -.10 \\
NEOPI-R domain scales & & & & & \\
Neuroticism & -.01 & -.05 & -.01 & -.00 & .00 \\
Extraversion & .18 & $.21^{*}$ & .17 & .15 & .12 \\
Openness to Experience & $.22^{*}$ & $.33^{* * *}$ & $.36^{* * *}$ & $.34^{* * *}$ & $.31^{* * *}$ \\
Agreeableness & -.14 & -.06 & -.11 & -.12 & -.14 \\
Conscientiousness & .02 & $-.20^{*}$ & -.16 & $-.24 *$ & $-.19^{*}$ \\
Facets of Openness & & & & & \\
O1 Fantasy & .18 & $.42^{* * *}$ & $.40^{* * *}$ & $.42^{* * *}$ & $.31^{* * *}$ \\
O2 Aesthetics & .15 & .08 & .10 & .10 & .05 \\
O3 Feelings & .14 & .15 & .18 & .17 & .13 \\
O4 Actions & .17 & $.29 * *$ & $.27 * *$ & $.30^{* *}$ & $.27^{* *}$ \\
O5 Ideas & .08 & .05 & .14 & .01 & .17 \\
O6 Values & .11 & $.23^{*}$ & $.23^{*}$ & $.26^{* *}$ & $.22^{*}$ \\
\hline
\end{tabular}

Note. NP, WP, and $\mathrm{OP}=$ number, wittiness, and originality of punch lines created, respectively; WI $=$ subjects' wit; FA $=$ subjects' fantasy $(N=110)$.

${ }^{*} p<.05 ;{ }^{* *} p<.01 ;{ }^{* * *} p<.001$.

were predictive of some aspects of wit, it was SE5, the facet akin to non-bona fide mode of communication (see Table 1) that yielded the highest coefficients ( $r$ from -.30 to -.41 ; average $r$ for the other facets: -.30 ).

Table 4 shows that seriousness is a better predictor of wit than conscientiousness (the best predictor of seriousness in the FFM) supporting the view that specific traits might be more useful for the study of humor phenomena than general personality dimensions. Openness to experience is the best predictor of quality of humor creation among the FFM dimensions; in particular the facet of openness to fantasy. Openness to actions and values were also significant. A stepwise regression analysis with seriousness, psychoticism, conscientiousness, and openness to experience as predictors and the various indices of wit as criteria yielded that for quantity of humor creation conscientiousness entered the equation as the second variable (after STCI-T SE) and improved the prediction to $.33(p=.002)$; thus, the conscientious among the non-serious wrote the most punch lines. However, for the quality indices openness entered the equation, and boosted the multiple correlations to the size of .50 (CPPT WP), .45 (CPPT OP), .49 (CPPT WI), and .41 (CPPT FA). The effects of psychoticism and conscientiousness diminished after trait seriousness entered the 
equation. Thus, the person of wit is low in seriousness (or conscientiousness/high in psychoticism) and open to experience. This confirms the assumption that creativity or fantasy supplements the effects of seriousness.

Trait seriousness and humor appreciation. Trait seriousness was introduced as a form of humorlessness; the serious individuals prefer to involve themselves in profound and significant things rather than wasting time with shallow or frivolous ones suggesting a positive correlation with the 3 WD total score of aversiveness of humor. Moreover, facet SE3 (see Table 1) refers to an orientation towards "sense" which allows us to predict a negative correlation with enjoyment of nonsense. Additional and refined hypotheses can be based on Raskin's (1992, see also Raskin this volume) typological approach that links sense of humor, seriousness and commitment to truth in communication. Three types of people are distinguished on a dimension ranging from the idealized poles of humorless to maximum sense of humor: Type 1 (serious/humorless) individuals will reject all forms of humor. While Type 2 (semi-serious/semi-humorous) individuals will be able to enjoy humor with a truth/message, Type 3 (maximal sense of humor, non-serious) individuals neither need nor expect any serious message in a joke to enjoy it. Applying this model to humor appreciation as assessed by the 3 WD humor test, Ruch (1993b) hypothesized that seriousness will correlate positively with aversiveness of humor, negatively with funniness of nonsense humor (i.e., humor with left over traces of incongruity or unresolvable incongruity), and in an inverted-u shape with funniness of incongruity-resolution humor (i.e., humor in which the incongruity can be completely resolved).

Table 5 shows that trait cheerfulness and bad mood was not correlated with humor appreciation. Individuals high in trait seriousness knew fewer of the $3 \mathrm{WD}$ jokes and cartoons (than the low scorer) demonstrating less interest in humor. While they did not overall find the jokes less funny, the habitually nonserious individuals preferred nonsense over incongruity-resolution humor; indeed, the structure preference index yielded the highest coefficient. More important, trait seriousness correlated negatively with $\mathrm{NON}_{\mathrm{f}}$ (i.e., humor in which the resolution information gives the appearance of making sense out of incongruities without actually doing so), confirming the assumption that the non-serious (Raskin's Type 3 ) individuals are the ones who enjoy humor that does not necessarily need to contain a super-truth or a message. Furthermore, trait seriousness correlated positively with aversiveness of the three humor categories combined (INC-RES, NON, and SEX); the serious (Raskin's Type I) individual rejected all forms of humor most strongly.

The hypothesis of an inverted-u shape relationship between trait seriousness and funniness of incongruity-resolution humor was tested in a polynomial regression analysis involving linear and quadratic trends. Indeed, there was a non-linear rela- 
Table 5. Correlations between the STCI-T $<60>$ and the 3 WD humor appreciation scales

\begin{tabular}{lcccccc}
\hline & Funny & Aversive & Known & INC-RES $_{\mathrm{f}}$ & NON $_{\mathrm{f}}$ & SPI $_{\mathbf{f}}$ \\
\hline STCI-T<60> scales & & & & & & \\
Cheerfulness & .12 & -.09 & -.03 & .12 & .11 & -.02 \\
Seriousness & -.02 & $.24 *$ & $-.20^{*}$ & .11 & $-.21^{*}$ & $-.29 * *$ \\
Bad mood & -.08 & .13 & .19 & -.15 & -.07 & .08 \\
\hline
\end{tabular}

Notes. INC-RES $\mathrm{f}_{\mathrm{f}}$ and $\mathrm{NON}_{\mathrm{f}}=$ funniness of incongruity-resolution and nonsense humor, respectively; $\mathrm{SPI}_{\mathrm{f}}=$ Structure Preference Index $(N=110)$.

$* p<.05 ;{ }^{* *} p<.01$.

tionship $(r=.31 ; \mathrm{F}[2,107]=5.84 ; p=.0039)$ between trait seriousness and NC-RES $\mathrm{f}_{\mathrm{f}}$, i.e., the semi-serious (Raskin's Type 2) individual enjoyed humor more containing punch lines in which the surprising incongruity can be completely resolved than the ones very low or high in trait seriousness. However, in addition to the quadratic $(t=-3.20 ; p=.0018)$ trend also the linear $(t=3.33 ; p=.0012)$ trend was positive and significant, indicating that the low serious individuals find them even less funny than the high serious.

Thus, the results provide support for the theory and the derivation and operationalization of the hypotheses. While the coefficients obtained were rather low, one has to bear in mind that the correlation among the humor appreciation scales were

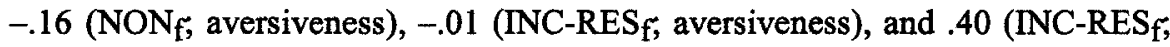
$\mathrm{NON}_{\mathrm{f}}$ ); i.e., they were uncorrelated or only slightly correlated themselves. Hence, their individual correlations with seriousness can not get particularly high. A canonical regression analysis was performed and yielded two significant roots that linked the set of the three humor appreciation variables with trait seriousness (regular scores and squared normalized values); the canonical correlation coefficients being $.38\left(\chi^{2}[6]=24.51 ; p<.001\right)$ and $.27\left(\chi^{2}[2]=7.89 ; p=.019\right)$. Likewise, adding humor creation to the analysis makes trait seriousness appear even more powerful; the canonical correlation coefficient of the first axis increases to $.56\left(\chi^{2}[16]=\right.$ $55.05 ; p<.0001)$ and the one for the second axis to $.38\left(\chi^{2}[7]=16.29 ; p<.05\right)$. Thus, trait seriousness-unseriousness can be seen as a variable globally underlying the mental processes involved in both humor creation and appreciation (rather than a predictor of a specific aspect of humor appreciation or creation).

Factor analytic studies of humor scales

The previous section confirmed that trait cheerfulness and seriousness predict a variety of humor behaviors and experience. Many of these behaviors (e.g., liking to 
laugh, appreciating humor, liking to entertain others, being witty, maintaining humor under adversity) are often used as markers of the sense of humor in contemporary inventories. Thus, one can expect the STCI constructs to correlate highly with sense of humor scales and to share the same factor space. More precisely, trait cheerfulness might form a social-affective axis (predicting laughter, robustness of mood, entertaining others etc.) and trait seriousness might mark a mental axis (predicting wit, humor preference etc.) in the sense of humor.

The first factor analytic study (Ruch 1994b) comprised five humor inventories with 10 scales and yielded two factors of "surgency" and "restraint vs. expressive" (cheerfulness and seriousness were suggested as alternative labels which represent the context of humor more appropriately). The second study utilized even more sense of humor scales (comprising 13 subscales) and the 11 facets of trait cheerfulness and seriousness (Köhler \& Ruch 1996). A joint factor analysis confirmed that all sense of humor scales and the facets of cheerfulness merged in a potent first factor. This broad factor was composed of elements, such as a prevalent cheerful mood, the tendency to smile or laugh and to be merry, coping humor and cheerful composedness, initiating humor/liking to entertaining others, liking of humor stimuli, and a positive attitude about things being related to cheerfulness and playfulness. Again, while they all shared a common loading on the cheerfulness factor, the scales differed with respect to whether they were also loaded negatively by seriousness, the second factor, and how marked this loading was. While the more affect-related humor scales were close to the axis, the sense of humor scales involving mentality or attitudes were additionally loaded negatively by seriousness and thus located in the cheerfulness/low seriousness quadrant. Nevertheless, scales of humor creation loaded primarily on cheerfulness rather than seriousness since they emphasize the entertainment aspect.

In a third study (Ruch \& Carrell in press) the STCI and a sense of humor scale distinguishing eight components of the sense of humor (McGhee 1996) was administered to American $(N=263)$ and German $(N=151)$ samples. In a joint factor analysis of all 24 subscales the facets of cheerfulness and the sense of humor components (enjoyment of humor, laughter, verbal humor, finding humor in everyday life, laughing at yourself, and humor under stress) formed a potent first factor. Seriousness and bad mood formed the other factors, which were loaded by the STCI-T facets but also by scales of seriousness and negative mood, playfulness and positive mood which form important facets in McGhee's model of the sense of humor. Obviously, the relevance of trait seriousness and bad mood for the sense of humor can only be demonstrated if the inventories sampled also cover humorlessness.

While all facets of the sense of humor as measured by current questionnaires (including aspects of humor in the more narrow sense, such as laughing at yourself, humor under stress, coping humor) shared the same factor space, the study of the re- 
lationship between the STCI constructs and sense of humor as undertaken so far is limited by the fact that the identification of the number and nature of dimensions involved in sense of humor utilized the existing pool of sense of humor instruments rather than starting from a comprehensive set of markers of humor and humorlessness. Recently, Craik et al. (1996) undertook such an endeavor for the domain of everyday humorous conduct and identified five humorous styles from a comprehensive list of statements. Within this framework, we expect cheerfulness to correlate with socially warm and benign humor styles, while seriousness and bad mood might go along with repressed and inept humor styles, respectively.

\section{The humorous temperament and personality}

When outlining his concept of cheerfulness, Lersch (1962) gave descriptions of the associated behaviors and traits. For example, he claimed that a cheerful person has a positive attitude towards the world, is able to enjoy things, is sociable and meets fellow creatures with goodwill and benevolence. Cheerfulness and nervousness, but also envy, distrust, malice, and all sorts of aggression tend to exclude each other. It is open to empirical examination whether these relationships, and the ones postulated for the other concepts, can be confirmed for the present conceptualization.

Based on Lersch's descriptions and on other considerations we hypothesized that cheerfulness correlates positively with positive affectivity, extraverted and pro-social traits, and negatively with traits of negative affectivity (Ruch 1994a; Ruch \& Köhler in press). Bad mood was expected to show an inverse pattern, however, more strongly aligned with the negative qualities. Thus, bad mood would correlate positively with traits of negative affectivity and resignation or antagonism, and negatively with extraversion. Given the description of the serious person, we expected seriousness to be correlated with traits of socialized impulse control and thinking introversion.

To study the relationship between cheerfulness, seriousness and bad mood and a broader list of personality traits, 100 German adults ( 53 female, 47 male, aged from 18 to 51 years; $M=26.05, S D=7.82$ years) answered the trait-form of the STCI and the German version of the Personality Research Form (PRF; Jackson 1974), a questionnaire containing 254 statements in a yes/no answer-format measuring a selected and revised list of needs postulated by Murray (1938). Table 6 confirms that the correlational profile of the three humorous temperaments was very different and in agreement with the expectations. Trait cheerfulness correlated positively with need for play, affiliation, exhibition, dominance, and nurturance. Seriousness yielded positive correlations with endurance, order, understanding, and achievement and negative ones with impulsivity, play, and affiliation. Bad Mood correlated posi- 
Table 6. Relationship between the STCI-T $<60>$ and the content scales of the PRF

\begin{tabular}{lccc}
\hline PRF content scales & Cheerfulness & Seriousness & Bad Mood \\
\hline Achievement & -.01 & $.30^{* *}$ & -.17 \\
Affiliation & $.50^{* * *}$ & $-.23^{*}$ & $-.41^{* * *}$ \\
Aggression & .10 & -.06 & $.24^{*}$ \\
Dominance & $.26^{* *}$ & .06 & $-.28^{* *}$ \\
Endurance & .16 & $.39 * * *$ & $-.33^{* * *}$ \\
Exhibition & $.37^{* * *}$ & -.15 & $-.31^{* *}$ \\
Harmavoidance & -.10 & -.05 & .07 \\
Impulsivity & .08 & $-.54^{* * *}$ & .12 \\
Nurturance & $.22^{*}$ & .02 & -.02 \\
Order & .00 & $.34 * * *$ & -.11 \\
Play & $.59 * * *$ & $-.48^{* * *}$ & $-.29 * *$ \\
Social Recognition & .09 & -.03 & .11 \\
Succorance & .03 & -.14 & $.27^{* *}$ \\
Understanding & -.13 & $.34 * * *$ & .01 \\
\hline
\end{tabular}

Note. $N=100$.

${ }^{*} p<.05 ;{ }^{* *} p<.01 ;{ }^{* * *} p<.001$.

tively with aggression and succorance and negatively with affiliation, endurance, exhibition, play, and dominance.

It is important to note that while playfulness correlated negatively with seriousness, the positive correlation with cheerfulness was higher. The highest coefficient was found for facet CH5 $(r=.60, p<.001, \mathrm{df}=98)$; i.e., the cheerful interaction style. Thus, playfulness - as measured by the PRF - is not simply the opposite of seriousness. The need for play is most characteristic for the unserious among the cheerful individuals. Some of the needs clearly differentiate between the two (positively intercorrelated) forms of humorlessness; for example, endurance correlated positively with seriousness but negatively with bad mood.

A more parsimonious way to study the link between the humorous temperaments and personality is to locate the STCI constructs in comprehensive frameworks, such as the Eysenckian PEN system (e.g., Eysenck \& Eysenck 1985), the five factor model (FFM) of personality, or models of affectivity. With the aim to clarify these relationships, the STCI-T was applied together with the Eysenck Personality Questionnaire (EPQ-R; Eysenck et al. 1985) - a measure of the three superfactors of Psychoticism (or P), Extraversion (or E), and Neuroticism (or N) - and two measures of the FFM, namely the NEOPI-R (Costa \& McCrae 1992) and the BFQ (Caprara et al. 1993) in several samples (Ruch 1994a; Ruch \& Köhler 1997; Ruch $\&$ Weber 1994). Table 7 shows the major results from these studies. Irrespective of the measure, cheerfulness was associated with Extraversion/Energy, Agreeableness/ 
Table 7. The STCI-T<60> scales and the PEN and five-factor models of personality

\begin{tabular}{lccc}
\hline Personality inventories & Cheerfulness & Seriousness & Bad Mood \\
\hline EPQ-R $(N=368)$ & & & \\
Psychoticism & -.03 & $-.47^{* * *}$ & -.04 \\
Extraversion & $.60^{* * *}$ & $-.38^{* * *}$ & $-.43^{* * *}$ \\
Neuroticism & $-.37^{* * *}$ & $.24^{* * *}$ & $.69^{* * *}$ \\
NEOPI-R $(N=110)$ & & & \\
Neuroticism & $-.37^{* * *}$ & .13 & $.65^{* * *}$ \\
Extraversion & $.68^{* * *}$ & $-.30^{* *}$ & $-.52^{* * *}$ \\
Openness & $.31^{* * *}$ & $-.24^{*}$ & $-.29^{* *}$ \\
Agreeableness & $.27^{* *}$ & .05 & $-.31^{* * *}$ \\
Conscientiousness & .02 & $.48^{* * *}$ & $-.19^{*}$ \\
BFQ $(N=301)$ & & & \\
Energy & $.37^{* * *}$ & $-.21^{* *}$ & $-.28^{* * *}$ \\
Friendliness & $.39^{* * *}$ & $-.26^{* *}$ & $-.33^{* * *}$ \\
Conscientiousness & $-.18^{* *}$ & $.53^{* *}$ & .07 \\
Emotional stability & $.24^{* * *}$ & .10 & $-.60^{* * *}$ \\
Openness & .09 & .03 & -.10 \\
\hline
\end{tabular}

$* * p<.01 ; * * * p<.001$.

Friendliness, and Emotional Stability/low Neuroticism. Thus, cheerfulness was highest among philanthropic sanguine (i.e., stable extravert) types. Bad mood yielded the opposite pattern, and, as expected, the contribution of $\mathrm{N}$ was stronger than the one of $\mathrm{E}$. Thus, predominantly the disagreeable neurotic introvert was prone to bad mood. Finally, seriousness was consistently associated with low Psychoticism/Conscientiousness and Introversion.

The pattern found for $\mathrm{E}$ and $\mathrm{N}$ parallels the one found for the two orthogonal dimensions of positive (PA) and negative (PA) affectivity (e.g., Watson et al. 1988). While cheerfulness correlated highly positively with $\mathrm{PA}$ and to a lesser extent negatively with NA, bad mood correlated highly positively with NA and (less so) negatively with PA (Ruch \& Köhler in press).

\section{Conclusions}

The results obtained so far provide evidence that cheerfulness, seriousness, and bad mood as states and traits are relevant to the study of humor. They account for a variety of phenomena, such as appreciation of types of humor, wit, keeping or losing humor when facing adversity, or readiness for exhilaration and laughter. There is also support for the view that these more narrow concepts are better predictors of humor phenomena than the global personality concepts (see also Ruch 1997). 
Since the concepts are relatively new, so far only a few issues of the classical canon of research questions associated with personality traits have been touched. While it is not necessary to discuss the whole agenda, a few open questions will be addressed exemplarily. One issue is to study these concepts in relation to other areas of humor not covered so far. For example, experimental induction of cheerfulness, seriousness, and bad mood prior to exposure to humor would allow the investigation of these states as potential causal factors. Furthermore, it might be of interest to study to what extent and by what means the individuals' location on these affective and mental dimensions can be changed in a lasting way or even permanently. Obviously, for such studies the modified versions of the state scale (with the instruction referring to longer time spans) would be preferable, because they are more sensitive to change. Likewise, the hypothesis mentioned in the introduction that certain (perhaps negative) life experiences together with acquired insights into human nature and human existence enhance humorous attitude/world view among individuals with a cheerful temperament deserves closer attention. The finding that agreeableness was involved in the prediction of cheerfulness is compatible with this hypothesis, since humor in the narrow sense includes benevolence and tolerance. Now, preferably, a longitudinal study is needed with trait cheerfulness assessed prior to the life events (so that it is not itself affected by them) and an appropriate measure for this understanding of humor assessed after these events. The notion of a temperamental trait requires the study of its genetic and physiological bases. Finally, since trait cheerfulness proved to be a predictor of robustness of mood in the experimental studies, it might be worthwhile to examine its role in coping with stress, in ameliorating health, etc. The global hypothesis put forward is that trait cheerful individuals have a better "psychological immune system", protecting them against the negative impact of the annoyances and mishaps they meet in everyday life and enabling them to maintain good humor under adversity.

\section{Notes}

The preparation of this chapter was facilitated by a Heisenberg grant (Ru 480/1-1) from the German Research Council and by a DFG-grant (Ru 480/5-1) to the senior author. Thanks to Claudia Esser, Michael Freiss, Bettina van Lierde, Christoph van Thriel, and Armin Weber for collecting parts of the data. 